\title{
Venous drainage of the heart of the red fox (Vulpes vulpes)
}

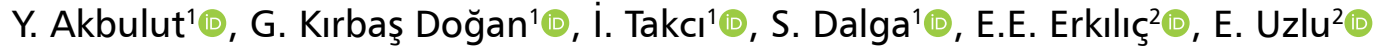 \\ ${ }^{1}$ Department of Anatomy, Faculty of Medicine, Kafkas University, Kars, Turkey \\ 2Department of Internal Medicine, Faculty of Veterinary Medicine, University of Kafkas, Kars, Turkey
}

[Received: 2 January 2021; Accepted: 5 March 2021; Early publication date: 9 April 2021]

Background: This study was carried out to reveal the coronary venous system of the red fox (Vulpes vulpes) heart. The hearts used in the study were obtained from six red foxes that were brought to the Kafkas University Wildlife Rescue and Rehabilitation Centre after serious injuries due to firearms or traffic accidents and could not be saved despite all interventions.

Materials and methods: Latex was injected from the cranial vena cava and caudal vena cava to expose the coronary vasculature. Hearts were photographed after dissection.

Results: It was determined that venous drainage of the red fox heart was provided by the great cardiac vein, middle cardiac vein, right cardiac veins, and the smallest cardiac veins. The strongest of these veins was determined to be the paraconal interventricular vein with a diameter of $3.03 \pm 0.44 \mathrm{~mm}$. It was determined that the paraconal interventricular vein was accompanied by a strong vein with a diameter of $2.09 \pm 0.43 \mathrm{~mm}$ in five of six fox hearts examined. It was observed that left atrial oblique vein participated in the formation of the coronary sinus in four hearts, and the great cardiac vein, middle cardiac vein, and the left marginal ventricular vein were seen to be drained into the coronary sinus in the other two hearts. It was determined that the paraconal interventricular vein and middle cardiac vein collected the venous blood of septum interventriculare via septal veins in all hearts.

Conclusions: In this study, the smallest cardiac veins were clearly identified for the first time, and the myocardial bridge was revealed in a wild animal for the first time. (Folia Morphol 2022; 81, 2: 343-349)

Key words: red fox, cardiac veins, coronary sinus, heart

\section{INTRODUCTION}

The red fox (Vulpes vulpes), which is the largest member of the true foxes and the most abundant wild species of the carnivores, can be found across the entire Northern Hemisphere from the Arctic Circle to North Africa, North America, and Eurasia. It is listed as a least concern species by the International Union for Conservation of Nature [15].

The great cardiac vein, the middle cardiac vein, the right cardiac veins, and the smallest cardiac veins comprise the coronary venous system of the heart, which is the centre of circulatory system. The great

Address for correspondence: Dr. Y. Akbulut, Department of Anatomy, Faculty of Veterinary Medicine, Kafkas University, 36100, Kars, Turkey, e-mail: yalcinakbulut@kafkas.edu.tr

This article is available in open access under Creative Common Attribution-Non-Commercial-No Derivatives 4.0 International (CC BY-NC-ND 4.0) license, allowing to download articles and share them with others as long as they credit the authors and the publisher, but without permission to change them in any way or use them commercially. 
cardiac vein, which collects the venous blood from the auricular surface, reaches the coronary sinus (CS) as the paraconal interventricular vein in the paraconal interventricular groove and the left circumflex vein in the coronary groove [10-12]. The middle cardiac vein in the subsinuosal interventricular groove on the atrial surface of the heart rises to the base from the apex of the heart along with the interventricularis subsinuosal artery, and opens to the CS. The CS is dilated at the terminal end of the great coronary vein. It is approximately $2 \mathrm{~cm}$ and 5 to $8 \mathrm{~mm}$ in diameter. The $\mathrm{CS}$ opens into the right atrium ventral to the termination of the caudal vena cava. The great cardiac vein and middle cardiac vein terminate at the CS, which is constituted by the great cardiac vein. Although the origin of the right cardiac veins varies considerably, they usually open directly into the right atrium. The smallest cardiac veins are found in all parts of the heart, and these veins carry more venous blood to the right atrium and the right ventricle $[8,10-12,17]$.

There have been several studies concerning venous circulation of the heart in different animal species $[4,9,14,23]$. However, there have been no studies concerning this topic in the red fox. The aim of this study was to describe the venous system of the red fox heart. We think this first study on the red fox heart could be a reference for future anatomical studies on the veins of domestic or wild carnivorous animal hearts.

\section{MATERIALS AND METHODS}

Conditional permission was obtained from the Kafkas University Animal Experiments Local Ethics Committee (KAU-HADYEK/2018-028, Kars, Turkey) to conduct this study. With this conditional permission, an application was submitted to the Ministry of Agriculture and Forestry, General Directorate of Nature Conservation and National Parks. This study was approved (21264211-288.04-2575700/05.09.2018). Perfusion was performed under general anaesthesia. For premedication xylazine (Rompun; Bayer, Istanbul, Turkey) was used at a dose of $1 \mathrm{mg} / \mathrm{kg}$. Subsequently, $10 \mathrm{mg} / \mathrm{kg}$ cyclohexanol (Ketalar; Parke-Davis, Istanbul, Turkey) were injected to achieve 45 minutes of general anaesthesia. The coronary veins of the hearts were washed with $0.9 \%$ saline, and then coloured-latex (ZPK-582-G Educational Scientific Products Ltd. West Sussex, UK) was injected via the caudal and cranial vena cava [5]. Latex-treated (red fabric dyed latex applied to arteries and blue coloured fabric-dyed latex to veins) hearts were kept at room temperature for 1 day and fixed in $10 \%$ formaldehyde for 10 days. Six red fox hearts ( 3 female and 3 male) of unknown age were used in this study.

The weight of the foxes ranged $7.35-8.68 \mathrm{~kg}$. The hearts were carefully dissected and photographed with a Kodak M320 camera. The diameters of all vessels were measured from where they originated. Electronic digital callipers (BTS, UK) were used to measure the hearts' characteristics. The terminology of this study was based on the Nomina Anatomica Veterinaria [13].

\section{RESULTS}

Length and diameter of the CS were measured as $21.13 \pm 3.55 \mathrm{~mm}$ and $4.24 \pm 2.41 \mathrm{~mm}$, respectively. The great cardiac vein, middle cardiac vein and left atrial oblique vein were found to be drained to the CS in four hearts. The great cardiac vein, middle cardiac vein and left marginal ventricular vein were found to be drained to the CS in two hearts, as well (Figs. $1 \mathrm{~B} ; 2 \mathrm{~B})$. Furthermore, arteries and veins forming the blood circulation of the heart often accompanied each other (Fig. 1A, B).

The great cardiac vein was found started as the paraconal interventricular vein in the incisura apices cordis where paraconal interventricular groove and subsinuosal interventricular groove intersected. Diameter of the paraconal interventricular vein in the paraconal interventricular groove was $3.03 \pm 0.44 \mathrm{~mm}$. The paraconal interventricular artery accompanied the great cardiac vein from the starting point (Fig. 1A). In all cases, the vein that drains the majority of the cardiac vein was the great cardiac vein. The great cardiac vein passed over the circumflex branch of the left coronary artery in four specimens (Fig. 1A) and passed under in two specimens. Five to seven collateral branches less than $1 \mathrm{~mm}$ in diameter from the right ventricle were drained to paraconal interventricular vein in three hearts (Figs. 1A, 2A, 3B). The left proximal collateral vein with a diameter of $1.45 \pm$ $\pm 0.60 \mathrm{~mm}$, the left distal collateral vein with a diameter of $1.50 \pm 0.51 \mathrm{~mm}$ and 5-10 thin collateral branches below $1 \mathrm{~mm}$ in diameter from the left ventricle were drained to paraconal interventricular vein This result showed that paraconal interventricular vein collected mostly venous blood from the left ventricle. Seven to eleven septal branches were found to be drained to paraconal interventricular vein, as well. In three of the hearts, a strong vein with a diameter of 

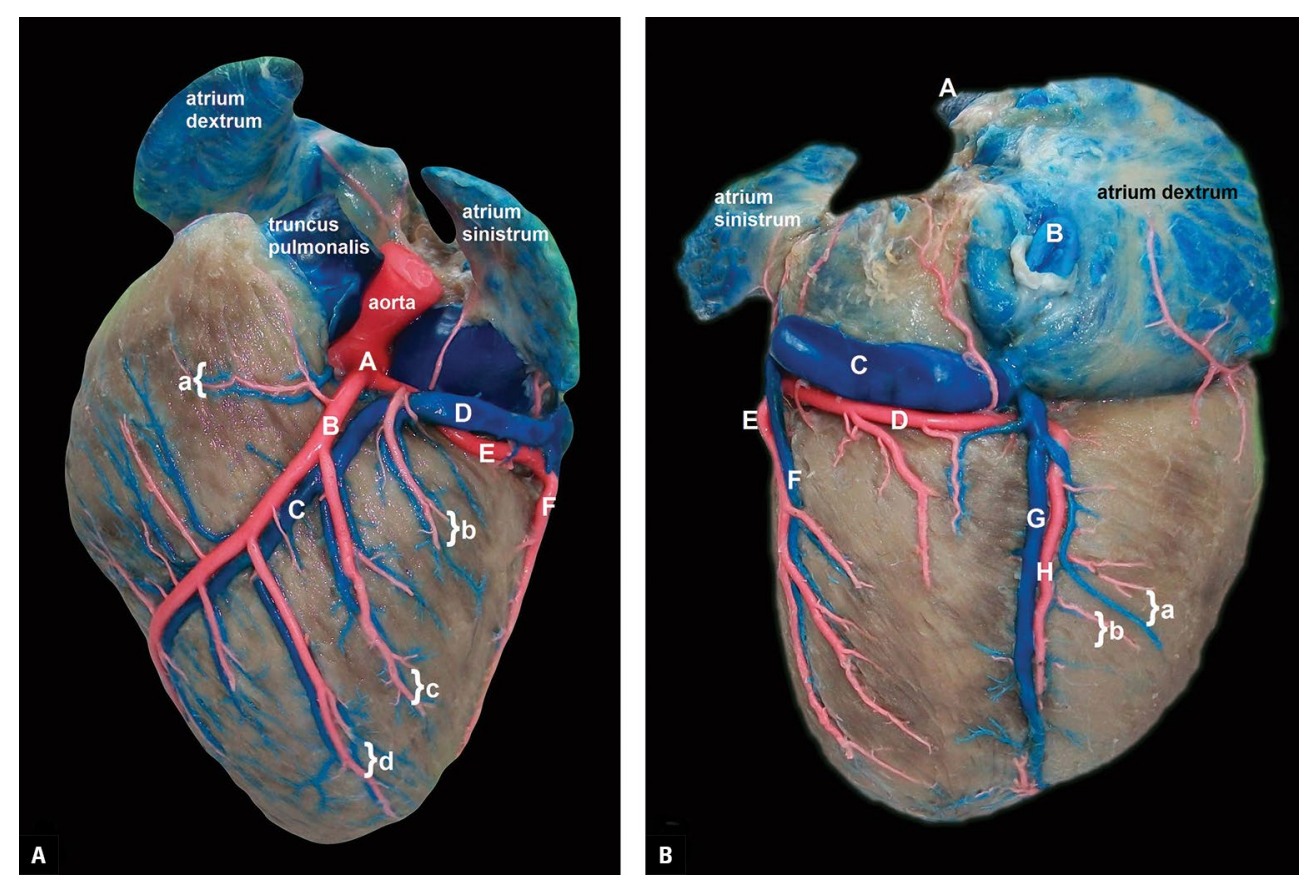

Figure 1. A. Cardiac veins and arteries in auricular surface of red fox heart; A — left coronary artery; B — paraconal interventricular artery; $\mathrm{C}$ - paraconal interventricular vein; $\mathrm{D}$ - left circumflex vein; $\mathrm{E}$ - left circumflex artery; $\mathrm{F}$ - left marginal ventricular artery; a — left conal vein and artery, $b$ - left proximal ventricular vein and artery, $c$ - left proximal collateral vein and artery, $d$ — left distal collateral vein and artery; B. Cardiac veins and arteries in atrial surface of red fox heart; A - cranial vena cava; B — caudal vena cava; $\mathrm{C}$ - coronary sinus; $\mathrm{D}$ - left circumflex artery; $\mathrm{E}$ - left marginal ventricular artery; $\mathrm{F}$ — left marginal ventricular vein; $\mathrm{G}$ - middle cardiac vein, $\mathrm{H}$ - subsinuosal interventricular artery, a - right proximal collateral vein and artery, $\mathrm{b}$ - right distal collateral vein and artery.
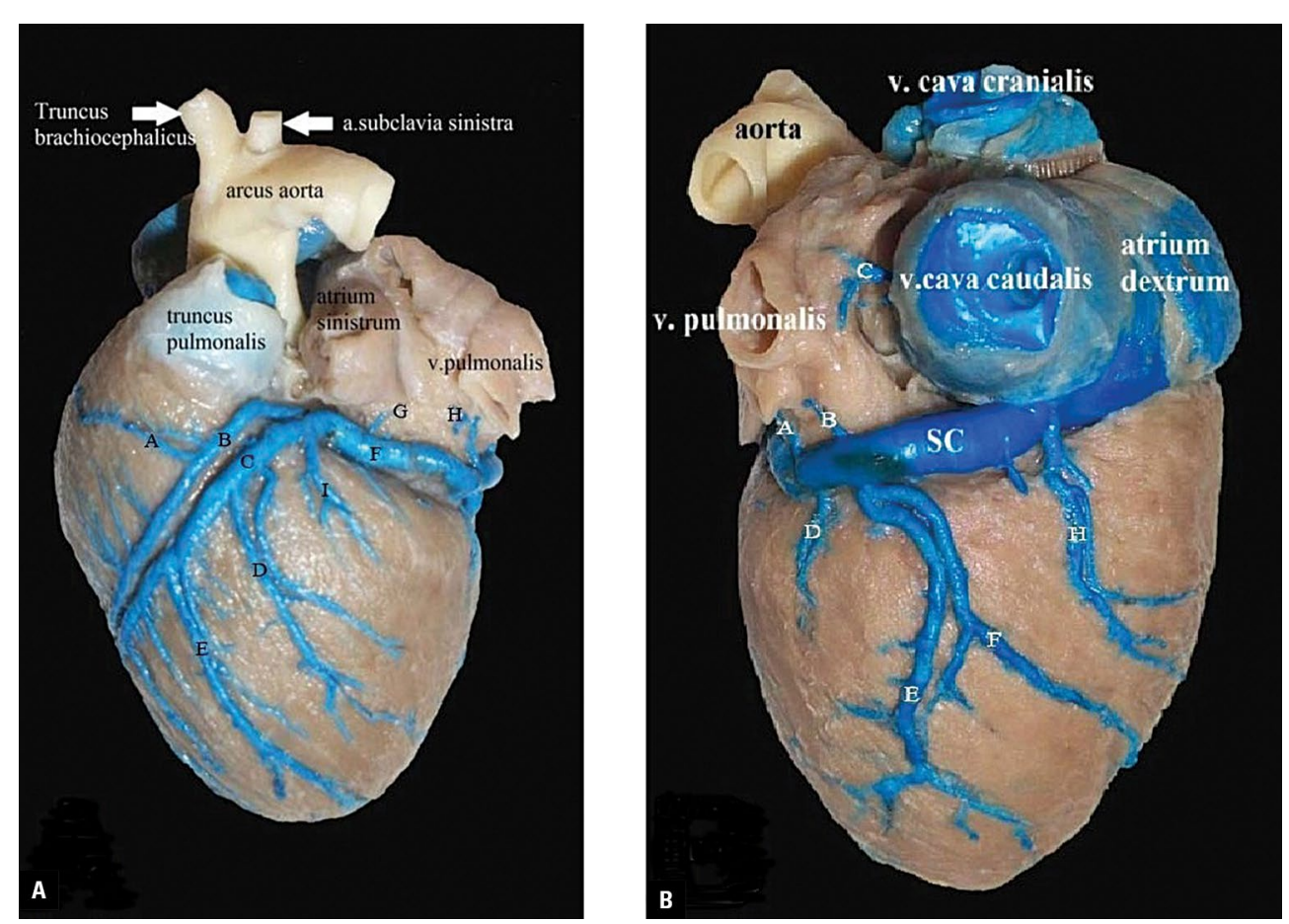

Figure 2. A. The great cardiac vein in the red fox; $A$ — left conal vein; $B$ - a strong vein; $C$ - paraconal interventricular vein; $D$ - left collateral proximal vein; $E$ - left collateral distal vein; $F$ — left circumflex vein; $G$ - left atrial proximal vein; $H$ — left atrial oblique vein; $I$ angular vein; B. The middle cardiac vein in the red fox; A — left atrial proximal vein; B — left atrial oblique vein; $\mathrm{C}$ - branch opens into the caudal vena cava; $\mathrm{D}$ — left proximal ventricular vein; $\mathrm{E}$ — left marginal ventricular vein; $\mathrm{F}$ — left distal ventricular vein; $\mathrm{H}$ — middle cardiac vein; SC — coronary sinus. 


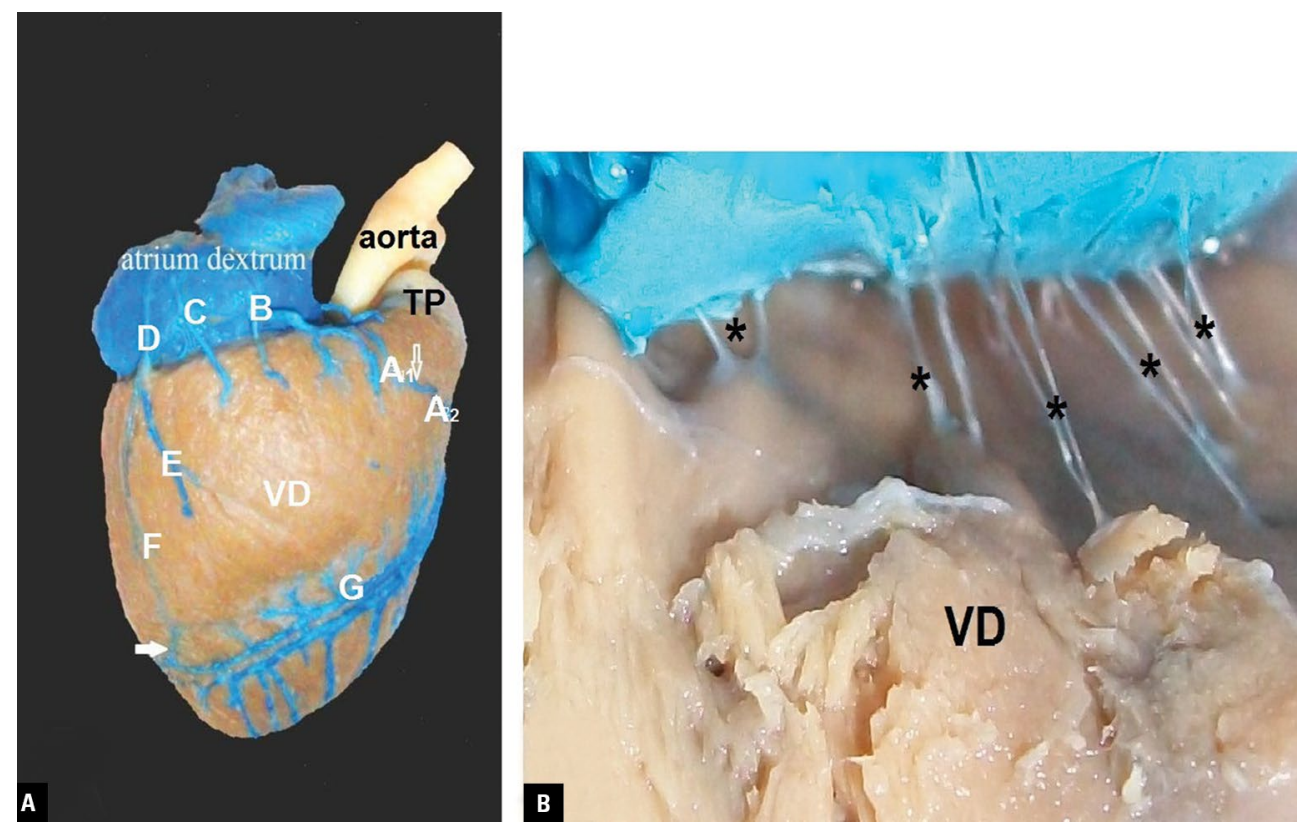

Figure 3. A. The right cardiac veins in the right ventricle of red fox heart; $A_{1-2}$ — left and right conal vein; $B$ - right proximal ventricular vein; $\mathrm{C}$ - right distal ventricular vein; $\mathrm{D}, \mathrm{E}, \mathrm{F}$ — right marginal ventricular vein; $\mathrm{G}$ - paraconal interventricular vein; $V D$ - right ventricle; $T P$ truncus pulmonalis; arrow — anastomosis; B. The smallest cardiac veins $\left({ }^{*}\right)$ in the right ventricle of red fox heart (B); VD — right ventricle.
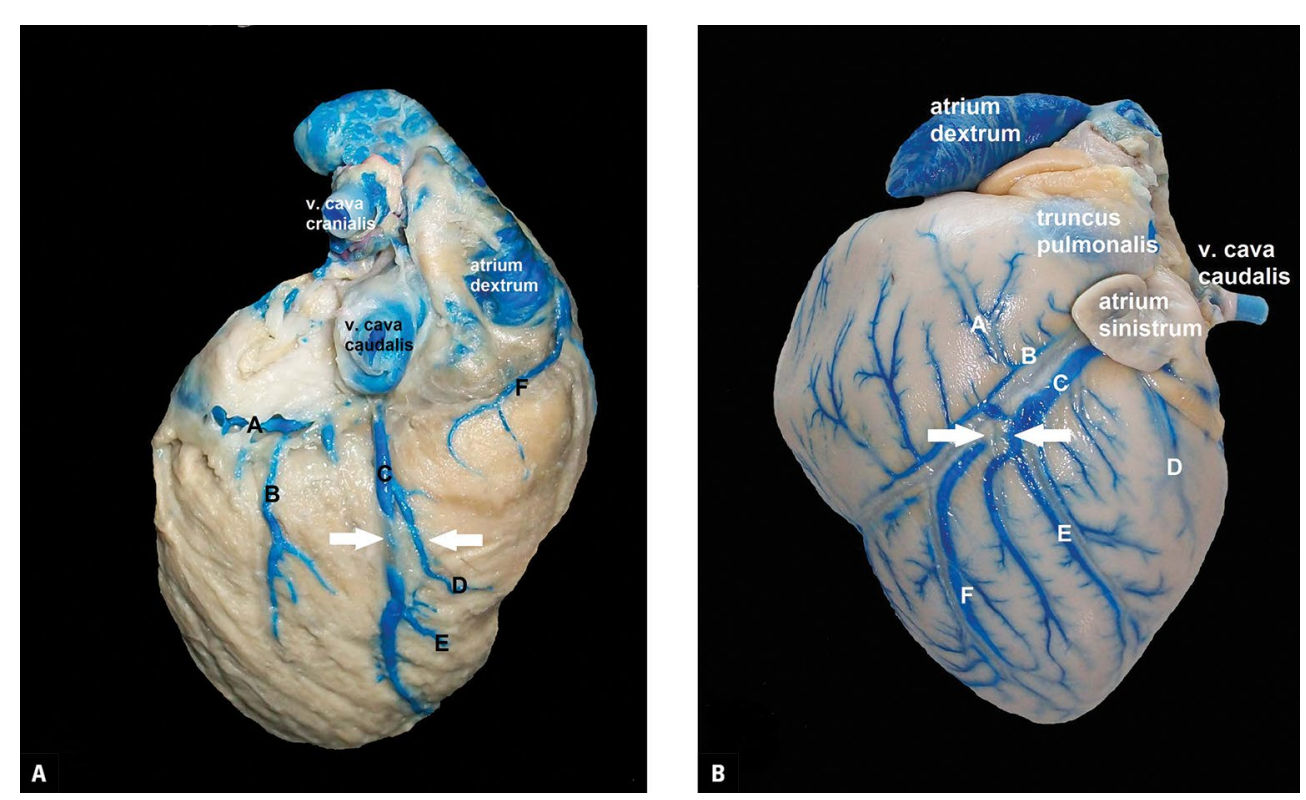

Figure 4. A. Myocardial bridge (arrow) on subsinuosal interventricular vein; A - coronary sinus; B — left distal ventricular vein; $C$ - subsinuosal interventricular vein; D — right collateral proximal vein; $\mathrm{E}$ — right collateral distal vein; $\mathrm{F}$ - right distal ventricular vein; $B$. Myocardial bridge (arrow) on paraconal interventricular vein; $A$ - left conal vein; $\mathrm{B}$ - a strong vein; $\mathrm{C}$ - paraconal interventricular vein; $\mathrm{D}$ - right proximal ventricular vein; $\mathrm{E}$ — right collateral proximal vein; $\mathrm{F}$ — right collateral distal vein.

$2.09 \pm 0.43 \mathrm{~mm}$, which was not mentioned in Nomina Anatomica Veterinaria [13], which was parallel to the paraconal interventricular vein was found. This strong vein only collected venous blood from the right ventricle. The diameter of paraconal interventricular vein decreased to $3.13 \pm 0.05 \mathrm{~mm}$ in hearts with this strong vein (Figs. 2A, 3A, 4B). The great cardiac vein continued as a left circumflex vein with a diameter of $3.51 \pm 0.09 \mathrm{~mm}$ in the coronary groove and ended by draining to the CS. In the coronary groove of the 
left circumflex vein, $1.21 \pm 0.12 \mathrm{~mm}$ diameter left atrial oblique vein and 2-3 atrial branches smaller than $1 \mathrm{~mm}$ in diameter from the left atrium were found to be drained (Fig. 2A, B). In addition, the left distal ventricular vein, left marginal ventricular vein and left proximal ventricular vein drained to left circumflex vein from the upper part of the left ventricle (Figs. 1A, B; 2A, B). In only one heart, the left marginal ventricular vein and left distal ventricular vein were opened with a common root to the left circumflex vein. The diameter of the middle cardiac vein in this heart decreased to $1.87 \mathrm{~mm}$ (Fig. 2B). The paraconal interventricular vein was found to be anastomosed with right marginal ventricular vein, right conal vein, right proximal ventricular vein and subsinuosal interventricular vein (Fig. 3A).

The diameter of the left marginal ventricular vein, which collects the venous blood of the upper $1 / 3$ of the atrial side of the heart, was $1.54 \pm 0.35 \mathrm{~mm}$. This vein found to be drained to the left circumflex vein in two hearts and to the CS in four hearts. The left marginal ventricular vein did not make an anastomosis with either the great cardiac vein or the middle cardiac vein (Figs. 1B, 2B).

The angular vein, which carries venous blood from the proximal part of the left ventricle, was joined at the point where the paraconal interventricular vein passes into the left circumflex vein (Fig. 3A). Angular vein was absent in two hearts (Fig. 1A).

The middle cardiac vein was determined to be drained to the CS by collecting venous blood from the right ventricle, left ventricle and interventricular septum of the hearts. The middle cardiac vein started as the subsinuosal interventricular vein in the subsinuosal interventricular groove and its diameter was $2.09 \pm 1.12 \mathrm{~mm}$. The artery of the same name accompanied the subsinuosal interventricular vein in the groove (Figs. 1B, 2B). The middle cardiac vein was a smaller vein than the great cardiac vein due to the small number of collateral and septal veins pouring into the middle cardiac vein and their small diameters. The diameters of the right distal collateral vein and the right distal collateral vein that drained the subsinuosal interventricular vein were measured as $1.30 \pm 0.28 \mathrm{~mm}$ and $1.42 \pm 0.38 \mathrm{~mm}$, respectively (Figs. 1B, 2B).

The right cardiac veins was found consisted of the right distal ventricular vein, the right marginal ventricular vein, the right proximal ventricular vein, and the right conal vein and drained the venous blood of upper $2 / 3$ of the right ventricle to the right atrium. The right and left conal veins made anastomosis in all hearts. In three hearts, right marginal ventricular vein was found to be anastomosed with paraconal interventricular vein (Fig. 3A). Among the right cardiac veins, the longest branch was right marginal ventricular vein and the thickest branch was right proximal ventricular vein (Fig. $3 \mathrm{~A}$ ).

Although different sizes of the smallest cardiac veins were detected in the right ventricle and right atrium of the fox hearts, these small veins were not found in other parts of the heart (Fig. 3B). Myocardial bridges were detected, one on the paraconal interventricular vein and the other on the subsinuosal interventricular vein (Fig. 4A, B).

\section{DISCUSSION}

Although there are several studies $[2,3,16,19]$ on the venous systems of the domestic carnivorous animals' hearts, there is only one study on the wild animals [18], which is built on the macroanatomical features of a tiger heart that died in a local ZOO. For the first time, with this study, the veins of the red fox heart were examined extensively.

We determined that the venous drainage of the red fox heart was provided by the great cardiac vein, the middle cardiac vein, the right cardiac veins, and the smallest cardiac veins. These findings are similar to those reported in Van cats [2], domestic cats [3], and dogs [19].

A study conducted by Piffer et al. [19] in adult dogs shows that the CS is mostly a continuation of the great cardiac vein, and it is formed by the great cardiac vein, the middle cardiac vein, the left atrial oblique vein and the left marginal ventricular vein. In our study, it was determined that the left distal ventricular vein participates in the formation of the CS in a heart in addition to the aforementioned veins. Unlike the Tuj sheep [4] and Roe deer [14], we determined that the left atrial oblique vein participated in the formation of the CS in the red fox.

The great cardiac vein was identified as the longest cardiac vein, as reported in the literature [2, 3], and the names were given according to the grooves it lies in. Similar to the Van cat [2], the red fox had a strong vein running parallel to the great cardiac vein, and this vein changed its dimensions due to the interventricular paraconal artery.

In our study, we found that the great cardiac vein passed over the circumflex branch of the left coronary 
artery in four hearts and passed under in two of the hearts. However, Maric et al. [16] reported that the great cardiac vein in both humans and dogs reaches the coronary groove, and the greatest cardiac vein crosses over the circumflex branch of the coronary artery (65\% in humans and $95 \%$ in canines), or passed under the left coronary artery $(12.5 \%$ in humans and $2.5 \%$ in canines) or the circumflex branch $(22.5 \%$ in humans and $2.5 \%$ in canines).

The great cardiac vein opened directly to the end of the coronary groove, and the venous blood of the interventricular septum together with the great cardiac vein were findings consistent with the literatures $[2,3,16,19]$. An anastomosis between the paraconal interventricular vein and the subsinuosal interventricular vein has been identified in domestic cats [3] and dogs [19], whereas no anastomosis was observed between the two veins or conal veins in the Van cat [2]. However, in our study, an anastomosis was detected between the paraconal interventricular vein and the subsinuosal interventricular vein, and between the paraconal interventricular vein and the right marginal ventricular vein and amongst the conal veins.

Nickel et al. [17] have reported that, except for the right conal vein, other veins formed the right cardiac vein opening into the right atrium either directly or via a common vessel in cats. Aksoy et al. [2] found that the right cardiac veins opened to the right atrium with a common root in three of six materials in Van cats, whereas the right conical vein, the right proximal ventricular vein, the right marginal ventricular vein, and the right distal ventricular vein formed the right semicircumflex vein. Contrary to this information, we did not find any vein similar to the right semicircumflex vein. In our study, we determined that the right cardiac veins directly opened to the right atrium separately.

Besoluk and Tipirdamaz [6] reported that the smallest cardiac veins are available in all parts of the heart except the left ventricle in the Angora goat, while it is available only in the right atrium and right ventricle in the Akkaraman sheep. Kabak and Onuk [14] have stated that the Roe deer only had the right atrium and right ventricle of the heart. The distributions of the smallest cardiac veins in the red fox are consistent with the findings of the Akkaraman sheep [6] and the Roe deer [14].

Dursun et al. [7] investigated the dog hearts and reported the existence of myocardial bridges at intervals on the atrial and auricular surfaces. In our study, only one myocardial bridge was observed on these surfaces. The myocardial bridge has been reported to occur in a range of $75-100 \%$, especially in ruminants $[1,20-22]$, but this rate was found only $33 \%$ in our study. Accordingly, it can be argued that some disorders related to the myocardial bridges, including death, are unlikely to be seen in the red fox.

\section{CONCLUSIONS}

To summarise, this is the first study that clearly demonstrates the configuration of the cardiac vessels of the red fox and compares them with the cardiac vessels of the other carnivores. The myocardial bridge was found for the first time in a wild animal with this study. Studies exhibiting the macroanatomical structures of the vessels of the red fox hearts can be extended and thus the emerged findings may contribute to future venous studies of other wildlife.

\section{Conflict of interest: None declared}

\section{REFERENCES}

1. Akbulut $Y$, Demiraslan $Y$, Aslan $K$, et al. The Coronary Arteries and Myocardial Bridges in Zavot-Breed Cattle. Kafkas Univ Vet Fak Derg. 2014; 20: 287-293, doi: 10.9775/ kvfd.2013.10066.

2. Aksoy G, Karadag H, Ozudogru Z. Morphology of the venous system of the heart in the van cat. Anat Histol Embryol. 2003; 32(3): 129-133, doi: 10.1046/j.14390264.2003.00444.x, indexed in Pubmed: 12823097.

3. Aksoy G, Karadag H, Soyguder Z. A macroanatomic investigation on the cardiac veins in the domestic cat. J Health Sci Univ Firat. 2001; 15: 315-324.

4. Aksoy G, Ozmen E, Kurtul i, et al. The Venous Drainage of the Heart in the Tuj Sheep. Kafkas Univ Vet Fak Derg. 2009; 15: 279-286, doi: 10.9775/kvfd.2009.015-a.

5. Aycan K, Bilge A. The investigation on the vascular system anatomy using plastic injection and corrosion method. J Faculty Med Univ Erciyes. 1984; 6: 545-552.

6. Besoluk K, Tipirdamaz S. Comparative macroanatomic investigations of the venous drainage of the heart in Akkaraman sheep and Angora goats. Anat Histol Embryol. 2001; 30(4): 249-252, doi: 10.1046/j.1439-0264.2001.00327.x, indexed in Pubmed: 11534331.

7. Dursun N, Asti NR, Tıpırdamaz S, et al. Macroscopic and microscopic investigations on the myocardial bridges in domestic animals. S U Vet Fak Derg. 1992; 8: 12-17.

8. Dursun N. Veteriner Anatomi. 12th ed. Medisan, Ankara, Turkey 2008.

9. Esperança Pina JA, Correia M, O’Neill JG, et al. Morphology of the veins draining the coronary sinus of the dog. Acta Anat (Basel). 1981; 109(2): 122-128, doi: 10.1159/000145374, indexed in Pubmed: 7018158.

10. Evans HE. Miller's anatomy of the dog. 3rd ed. Saunders, Philadelphia, PA, USA 1993. 
11. Ghoshal NG. Carnivore heart and arteries. In: Sisson and Grossman's the Anatomy of the Domestic Animals, 5th ed., Philadelphia and London 1975.

12. Ghoshal NG, Koch T, Popesko P. The venous drainage of the domestic animals. Saunders, Philadelphia 1981.

13. International Committee on Veterinary Gross Anatomical Nomenclature. Nomina Anatomica Veterinaria (NAV), 5th ed, World Association of Veterinary Anatomists, Hannover, Columbia, Gent, Sapporo, 2005.

14. Kabak M, Onuk B. Macroanatomic Investigations on the Venous Drainage of the Heart in Roe Deer (Capreolus capreolus). Kafkas Univ Vet Fak Derg. 2012; 18: 957-963, doi: $10.9775 / \mathrm{kvfd} .2012 .6841$.

15. Macdonald DW, Reynolds JC. Vulpes vulpes. International Union for Conservation of NatureRed List of Threatened Species. 2008, doi: 10.2305/iucn.uk.2008.rlts. t23062a9412884.en.

16. Marić I, Bobinac D, Ostojić $L$, et al. Tributaries of the human and canine coronary sinus. Acta Anat (Basel). 1996; 156(1): 61-69, indexed in Pubmed: 8960300.

17. Nickel R, Schummer A, Seiferle E. The anatomy of the domestic animals. Vol. 3: The circulatory system, the skin, and the cutaneous organs of domestic mammals. Verlag Paul Parey, Berlin, Germany 1981.

18. Perez W, Lima M. Brief description of the cardiac anatomy in a tiger (Panthera tigris, Linnaeus, 1758): a case report. Veterinární Medicína. 2008; 52(No. 2): 83-86, doi: 10.17221/2054-vetmed.

19. Piffer CR, Piffer MI, Santi FP, et al. Anatomic observations of the coronary sinus in the dog (Canis familiaris). Anat Histol Embryol. 1994; 23(4): 301-308, doi: 10.1111/j.14390264.1994.tb00479.x, indexed in Pubmed: 7887481.

20. Santos JW, Bombonato PP, Beletti ME, et al. Carneiro e Silva FO. Myocardial bridges in the bovine of Conchim race. Braz J Vet Res Anim Sci. 2000; 37: 35-43.

21. Severino RS, Bombonato PP. Occurrence of myocardial bridges in Gir, Guzera, Nelore and Indubrasil bovines. Braz J Vet Res Anim Sci. 1992; 29: 15-30.

22. Shinjo SK, Oba-Shinjo SM, Prates NE. Bovine myocardial bridge morphology and association with coronary atherosclerosis. Braz J Morphol Sci. 2004; 21: 95-98.

23. Yadm ZA. Origin, course and distribution of the venae cordis in the donkey. (equas asinus). Assiut Vet Med J. 1993; 28.2(56): 15-26, doi: 10.21608/avmj.1993.186369. 